\title{
Validation of the Persian version of family health climate scale (FHC-Scale) in Iranian families
}

\author{
Akram Kharazmi ${ }^{1}$, Jeannine M. Brant ${ }^{2}$, Moosa Sajjadi $^{3^{*}}$ (D, Mahdi Moshki ${ }^{4}$ and Leila Sadegh Moghadam ${ }^{5}$
}

\begin{abstract}
Background: Family health is an important issue which has attracted researchers from different fields. The present study aimed to validate the Persian version of the Family Health Climate Scale (FHC-Scale).

Methods: In this methodological research, a total of 620 individuals presenting to Comprehensive Healthcare centers affiliated with Mashhad University of Medical Sciences and Gonabad University of Medical Sciences were selected through random multistage sampling. Validation of the FHC-Scale was performed. First, the original scale was translated and back-translated. Then its content validity and construct validity were assessed using exploratory and confirmatory factor analysis. Reliability was assessed using internal consistency and stability. Data were analyzed using SPSS version 20 (IBM Corp., Armonk, NY, USA) and LISREL version 8.5 (SSI Inc., Skokie, IL, USA).

Results: Results of exploratory factor analysis showed that "physical activity" of family health climate scale (FHC-PA) has three dimensions: value, cohesion and information explaining $61.99 \%$ of the variance. "Nutrition" of family health climate scale (FHC-NU) had four dimensions of value, communication, cohesion and consensus explaining $66.19 \%$ of the variance. Internal consistency of the dimensions of (FHC-PA) ranged $0.82-0.85$ and that for FHC-NU ranged $0.82-0.84$. Confirmatory factor analysis revealed goodness of fit and confirmed family health climate scale (Nutrition and physical activity).
\end{abstract}

Conclusion: Results of the study revealed that the FHC-Scale has appropriate reliability and validity for Iranian families. Therefore, the Persian version of the scale can be used for assessing health-related aspects of family.

Keywords: Validation, Psychometric, Family health climate scale, FHC-scale, Iran

\section{Background}

The family is a complicated emotional system that is considered the major pillar and the initial organization of any society, where human emotions and intimate relations emerge. It can be said that family functioning affects society functioning in a direct and major way. In other words, a healthy society is composed of healthy families. Members of a family are connected through

\footnotetext{
* Correspondence: sajjadi1975@gmail.com

${ }^{3}$ Department of Medical-Surgical Nursing, Faculty of Nursing, Social

Development \& Health Promotion Research Center, Gonabad University of Medical Sciences, Gonabad, Iran

Full list of author information is available at the end of the article
}

biological, legal, emotional, geographical and historical bonds. As compared with other social groups, entering a family in the traditional sense is possible through giving birth to a child, adopting a child, caring for a child or getting married [1]. In Iran, the family is an indicator of the cultural value system. Recent decades have been exposed to structural changes that have affected all aspects of the family including communication among members, the emotional importance of members for one another, the meaning of family, economical functioning of family and the sexual roles [2]. Christensen believes the family is the cultural reflection of thousands of years of efforts 
to develop the members, improve their mental health, and reduce high-risk behaviors [3]. Therefore, given the continuous interactions that family members have within the family and with the society, it appears that family is the main focus of health in the society.

Based on a model developed in Iran, a healthy family is one with positive characteristics such as using healthy parenting styles, having skills for consulting with one another and decision making, and ensuring physical, mental and emotional needs of the members [4]. Healthy family functioning helps children to acquire a positive identity, increase independence, and reduce the incidence of behavioral and communication problems [5]. Currently, the comprehensive definition of family health is as follows: family health comprises a family's quality of life, health of each member, family interactions, spiritual indicators, nutrition, overcoming problems, living environment, entertainment, daily activities, sleep, and sexual desires [6].

Studies show that healthy functions of the family directly affect needs, objectives, satisfaction with life and emotional relations [7], and affect factors such as structure, roles, communication, perception and dynamic personality of members [8]. Research on the family has mainly focused on the influence of family members on one another, especially between couples and parentchild relations $[9,10]$.

Assessing family health is one of the major objectives of family therapists, that is used to identify challenges and propose solutions to help families reach their specific goals. A variety of tools are used to assess function and health of families, but no consensus has been reached on a single tool for this purpose [11]. One of the most important and influential factors for family health is maintaining physical activity and healthful nutrition $[12,13]$, but studies overall show that these topics are not well addressed in families [14]. Studies show Iranian families also pay less attention to physical activity and nutrition [15].

One assessment tool, which fits within the operational context of the family is the family health climate scale (FHC-Scale), developed by Niermann et al. (2014) [16]. The FHC-Scale, developed in Germany, was based on Bandura's social cognitive theory, which assumes that the environment and the individual determine their mutual relationship and affect one another's healthy behavior. The FHC-Scale has two scales, physical activity (FHC-PA) (14 items) and nutrition (FHC-NU) (16 items) scored on a Likert scale from totally false (0) to totally true (3).

The FHC-PA scale has three dimensions: 1) "Value" reflects the importance of physical activity for all members of the family, 2) "Cohesion" covers common physical activities and leisure activities of family members, and 3)
"Information" refers to the amount of searching for, sharing and using information related to sports and physical exercises. The FHC-NU scale has four dimensions: 1) "Value" focuses on family's emphasis on improving nutrition in their daily diet, 2) "Cohesion" reflects regular eating sessions of the family and the importance of eating together, 3) "Communication" covers the support and encouragement of family members for having a balanced diet 4) "Consensus" comprises the acceptance of family members' interests in nutritionrelated behaviors [16].

As mentioned, family health is the foundation of individual health within a given society, and measuring family health is an important area of research. The FHCScale is an attractive tool to measure family health in that it is comprehensive but has fewer items, which makes it more feasible for use, and reliability and validity indices are also established. Therefore, the purpose of this study was to translate and validate the Persian version of FHC-Scale in Iranian families.

\section{Methods \\ Participant recruitment}

The study population was comprised of families living in Mashhad and Gonabad cities in Iran. Given that Mashhad is the capital of Khorasan Razavi Province and people of different ethnicities live there, the results of the study can potentially be better generalized across the Iranian population. Several healthcare centers were first selected randomly from Mashhad and Gonabad, and then participants were selected by convenience and purposive sampling from among families covered by these centers. Sampling continued until sample size was appropriate for confirmatory factor analysis. The inclusion criteria were being Iranian, having at least one child over 14 years. Families with a history of divorce or history of admission to a psychiatry center were excluded. Accordingly, 620 families were finally selected. One member (father, mother, or child) from each family participated in the study. The present study was approved by the Gonabad University of medical science Research Ethics Committee (code: IR.GMU.REC.1395.102). Informed written consent was obtained from all participants.

\section{Translation of the scale}

The present study used Wilde et al.'s model (2005) [17] for translating and validating the scale. After obtaining the written approval of the scale developer, the FHCScale (FHC-PA and FHC-NU) was translated to Persian. Two translators who were competent in both German and Persian translated the scale to Persian. The two translations were compared and contrasted, and then merged into one final translation. In the next step, the Persian version was translated to German by two 
competent translators who had no contact with the first translators. The two translations were compared with the original scale by a lead translator and confirmed. Finally, psychometric assessment of the translated scale was conducted using face validity, content validity, construct validity (exploratory and confirmatory factor analyses), internal consistency and stability.

\section{Content validity}

The translated scale was next given to 10 faculty members experienced in scale development and familiar with family health to assess content validity of the items. They expressed their opinion of the relevance of each item based on Waltz and Bussel (1983) content validity index, so that content validity of the scale could be measured [18]. They also assessed and confirmed face validity of the scale. Following the review by experts, the scale was given to 10 family members for feedback on simplicity of the scale and understandability of items so that possible ambiguities could be further refined. The Persian version of FHC-Scale was finalized at this stage without major changes in its items.

\section{Data collection and analysis}

Participants were selected and briefed about the study objectives, and written informed consent was obtained. A demographics questionnaire (age, place of residence, economic status, parents' occupation, education level, family size, and level of daily activity) and the Persian version of the FHC-Scale was administered to one of the three family members (father, mother, or child) in every family. Completion of the questionnaire took 15 to $20 \mathrm{~min}$. Internal consistency reliability was measured using Cronbach's alpha, and stability was measured using an interclass correlation coefficient (ICC) with a two-week interval between measures. The literature notes that two or 3 weeks is an appropriate interval between the two tests [19].

Construct validity of the FHC-Scale was assessed and confirmed using exploratory (EFA) and confirmatory factor analyses (CFA). To this end, the study population was divided into two nearly equal subsamples: 300 individuals were assigned to calibration sample and 320 individuals were assigned to validation sample. EFA was used to analyze the calibration sample so that the model could be to examined and modified as necessary. The validation sample was used for validating the fit model.

Construct validity was performed with confirmatory factor analysis in Lisrel $^{\circ}$ version 8.5. Maximum likelihood estimation was used to assess model fit, using a variety of fitness indices as recommended in the literature $[20,21]$. The most important fitness indices used included Chi-square, SRMR, NFI, CFI, AGFI, GFI, and RMSEA. Appropriate values should be less than 0.06 for RMSEA, less than 0.08 for SRMR, and 0.9 or ideally greater than 0.95 for other indices [21, 22]. Before conducting CFA the assumptions of maximum likelihood estimation were assessed. Item distributions were inspected for multivariate normality using p-p plot and indicated normal distribution of the data. The correlation between the items for both scales were less than .80 .

\section{Results}

The sample included 620 family members. Mean age of the parents was 43.5 (10.8) and for the children 21.3 (6.5) years. The majority of fathers did not have a diploma, whereas the mothers were better educated noted by having a diploma and/or college degree. Mothers comprised $33.9 \%$ of the sample; fathers $26.9 \%$ and children $39.2 \%$. The demographic details of the study subjects are presented in Table 1.

\section{Scale validity and reliability}

Based on the scale reviews of the 10 experts regarding item relevance, the content validity index was found at 0.807 for the FHC-PA and 0.893 for the FHC-NU, indicating favorable content validity.

Table 2 illustrates the mean values of the physical activity and nutrition subscales and their dimensions in Iranian families as well as assessment of their internal consistency reliability as measured by Cronbach's alpha. All scales performed at 0.82 or greater. We also provided the inter-item correlation matrix for both the FHC-PA and the FHC-NU scales (See Additional file 1).

The traditional indicator for the reliability is Cronbach's alpha, but the composite reliability (CR) is more adequate to the Lisrel program. Because it prioritizes the variables according to their reliabilities, while the Cronbach's alpha is more sensitive to the number of variables in each construct. The $\mathrm{CR}$ value of 0.7 or greater considered as good reliability [10].

Convergent validity was assessed by Average Variance Extracted (AVE) the mean variance is extracted and measures how much manifest variables correlate positively with their respective latent variables (mean of the correlation). The literature considers there is convergent validity when the AVE value is greater or equal to 0.50 [10]. All dimension of the both scales have proper AVE and $C R$ values (Table 2).

Stability reliability of the FHC-scale was assessed by a test-retest methodology with 30 individuals. The ICC was 0.89 for the FHC-PA and 0.94 for the FHC-NU, indicating favorable stability for these scales.

\section{Factor analysis}

Exploratory factor analyses were performed with SPSS 20 using the Principal Component method with Varimax rotation. The Kaiser-criterion (eigenvalue $>1$ ) yielded three factors for the FHC-PA Scale and four factors for 
Table 1 Demographic characteristics of the participants $(n=620)$

\begin{tabular}{|c|c|c|}
\hline Variable & Mean & SD (Range) \\
\hline Age(year) & 34.8 & $14.3(14-85)$ \\
\hline Duration of the family formation (year) & 21.9 & $10.24(1-68)$ \\
\hline Physical activity per day(Hour) & 1.1 & $1.1(0-8.0)$ \\
\hline Category & $\mathbf{N}$ & $\%$ \\
\hline \multicolumn{3}{|l|}{ City } \\
\hline Mashhad & 373 & 60.2 \\
\hline Gonabad & 247 & 39.8 \\
\hline \multicolumn{3}{|l|}{ Family income } \\
\hline Less than enough & 65 & 10.5 \\
\hline Enough & 485 & 78.2 \\
\hline More than enough & 67 & 10.8 \\
\hline \multicolumn{3}{|l|}{ Education level (for father) } \\
\hline Illiterate & 66 & 10.8 \\
\hline Under diploma & 190 & 31 \\
\hline Diploma & 179 & 29.2 \\
\hline Bachelor's degree & 147 & 24.0 \\
\hline Master's degree. & 21 & 3.4 \\
\hline PhD degree & 9 & 1.5 \\
\hline \multicolumn{3}{|l|}{ Education level (for mother) } \\
\hline Illiterate & 61 & 9.9 \\
\hline Under diploma & 191 & 31.0 \\
\hline Diploma & 226 & 36.7 \\
\hline Bachelor's degree & 126 & 20.5 \\
\hline Master's degree. & 12 & 1.9 \\
\hline $\mathrm{PhD}$ degree & 0 & 0 \\
\hline \multicolumn{3}{|l|}{ Occupation (for father) } \\
\hline Self-employed & 299 & 48.9 \\
\hline Employee & 141 & 23.0 \\
\hline Worker & 70 & 11.4 \\
\hline Retired & 73 & 11.9 \\
\hline Unemployed & 13 & 2.1 \\
\hline Other & 16 & 2.6 \\
\hline \multicolumn{3}{|l|}{ Occupation (for mother) } \\
\hline Self-employed & 29 & 4.7 \\
\hline Employee & 73 & 11.8 \\
\hline Worker & 6 & 1.0 \\
\hline Retired & 45 & 7.3 \\
\hline Housewife & 457 & 73.8 \\
\hline Other & 9 & 1.5 \\
\hline \multicolumn{3}{|l|}{ Role in family } \\
\hline Father & 167 & 26.9 \\
\hline Mother & 210 & 33.9 \\
\hline Daughter & 140 & 22.6 \\
\hline Son & 103 & 16.6 \\
\hline
\end{tabular}

Table 1 Demographic characteristics of the participants $(n=620)$ (Continued)

\begin{tabular}{lll}
\hline Variable & Mean & SD (Range) \\
\hline Meals Together & & \\
breakfast & 2 & 0.3 \\
Lunch & 40 & 6.5 \\
dinner & 141 & 22.7 \\
Two meals & 103 & 16.6 \\
All three meals & 278 & 44.8 \\
None of meals & 55 & 8.9 \\
\hline
\end{tabular}

the FHC-NU Scale with eigenvalues greater than one respectively. Separate analyses were carried out for the physical activity scale and the nutrition scale. Exploratory factor analysis of the calibration sample $(n=300)$ showed that like the original scale, the FHC-PA is composed of three dimensions (value, cohesion, and information) and the FHC-NU is made-up of four dimensions (value, cohesion, communication, and consensus). Compared to the original scale, items of each dimension identically matched (Table 3). The three dimensions of FHC-PA scale explained $61.99 \%$ of the variance, and four dimensions of FHC-NU scale explained $66.19 \%$ of the variance. For both scales, the requirements for performing EFA were fulfilled (FHC-PA: $\mathrm{KMO}=0.853$, Bartlett's test of sphericity $\mathrm{X}^{2}=1763.13, \quad P<0.001$; $\mathrm{FHC}-\mathrm{NU}: \quad \mathrm{KMO}=$ 0.900 , Bartlett's test of sphericity $X^{2}=2235.75, P<0.001$ ).

To assess construct validity of the scale, CFA was performed using Lisrel-8.5. According to the factor analysis performed on the calibration sample, no change was made in items or in their placement as factor loading for all items was $>0.5$ and fit indices for both scales were highly favorable. CFA was then performed on the validation sample $(n=320)$ for further confirmation and validation. The fitness indices showed goodness of fit for the scales. The confirmatory factor analysis results for FHC-PA and FHC-NU scales are presented in Tables 4

Table 2 Mean scores and values of Cronbach's alpha, composite reliability and average variance extracted in the FHCNU and FHC-PA scales in Iranian families $(n=620)$

\begin{tabular}{llllll}
\hline scale & Dimension & Mean (SD) & $\mathbf{a}$ & AVE & CR \\
\hline FHC-NU scale & Value & $9.04(2.51)$ & 0.84 & 0.55 & 0.83 \\
& Cohesion & $9.57(3.39)$ & 0.82 & 0.51 & 0.83 \\
& Communication & $9.22(2.46)$ & 0.83 & 0.58 & 0.84 \\
& Consensus & $5.75(2.18)$ & 0.83 & 0.54 & 0.79 \\
FHC-PA scale & Value & $9.24(3.30)$ & 0.83 & 0.51 & 0.81 \\
& Cohesion & $11.10(3.06)$ & 0.85 & 0.55 & 0.75 \\
& Information & $5.95(3.15)$ & 0.82 & 0.57 & 0.74 \\
\hline
\end{tabular}

$S D$ standard deviation, $a$ Cronbach's alpha, AVE average variance extracted, $C R$ composite reliability 
Table 3 Factors, Items, and Factor Loadings in FHC-PA and FHC-NU scales

\begin{tabular}{|c|c|c|c|c|}
\hline Scales & Factors & Items & Mean (SD) & Factor Loading \\
\hline \multirow[t]{14}{*}{ FHC-PA } & Value & we make a point of being physically active during daily life. & $1.70(.91)$ & 0.770 \\
\hline & & it is normal to be physically active on a regular basis. & $1.96(.83)$ & 0.754 \\
\hline & & it goes without saying that we exercise and are physically active on a regular basis. & $1.75(.88)$ & 0.772 \\
\hline & & it is normal to be physically active in our leisure time. & $1.88(.81)$ & 0.703 \\
\hline & & we agree that physical activities are part of daily life. & $1.94(.78)$ & 0.569 \\
\hline & Cohesion & we like being together during physical activities (e.g. bike tours, hikes). & $2.26(.76)$ & 0.676 \\
\hline & & we enjoy exercising together. & $2.19(.78)$ & 0.823 \\
\hline & & we have fun doing physical activities together (e.g. bike tours, hikes). & $2.17(.81)$ & 0.834 \\
\hline & & we find it very pleasant to be physically active together. & $2.24(.75)$ & 0.797 \\
\hline & & we like spending time together in sports activities. & $2.17(.75)$ & 0.661 \\
\hline & Information & we watch TV-programs on physical activity and exercise. & $1.67(.96)$ & 0.715 \\
\hline & & $\begin{array}{l}\text { we explicitly look for the latest information on physical activity and exercise to stay } \\
\text { up to date. }\end{array}$ & $1.43(.95)$ & 0.851 \\
\hline & & we collect information (e.g. on the internet) on physical activity and exercise. & $1.41(.93)$ & 0.790 \\
\hline & & we read newspaper or magazine articles on fitness, physical activity, and exercise. & $1.58(.98)$ & 0.723 \\
\hline \multirow[t]{16}{*}{ FHC-NU } & value & a healthy diet plays an important role in our lives. & $2.33(.83)$ & 0.780 \\
\hline & & we naturally pay attention to eating healthfully. & $2.32(.76)$ & 0.764 \\
\hline & & we routinely eat healthfully. & $2.22(.78)$ & 0.741 \\
\hline & & it is normal to choose healthful foods. & $2.21(.76)$ & 0.723 \\
\hline & Communication & we are interested in articles (e.g. in magazines) on healthful nutrition. & $1.77(.95)$ & 0.599 \\
\hline & & we remind each other to pay attention to a healthful diet. & $1.93(.87)$ & 0.694 \\
\hline & & we talk about which foods are healthful. & $2.00(.86)$ & 0.779 \\
\hline & & we support each other to refrain from unhealthful things. & $1.99(.95)$ & 0.672 \\
\hline & & we talk about how to eat healthfully. & $1.99(.84)$ & 0.803 \\
\hline & Cohesion & we appreciate spending time together during meals. & $2.25(.76)$ & 0.752 \\
\hline & & everybody enjoys having meals together. & $2.38(.68)$ & 0.832 \\
\hline & & eating together is a part of our daily family life. & $2.22(.81)$ & 0.743 \\
\hline & & we enjoy meals most when we sit at the same table. & $2.35(.72)$ & 0.709 \\
\hline & Consensus & we rarely argue about food- or diet-related matters. & $1.87(.91)$ & 0.584 \\
\hline & & we agree on diet and nutrition. & $1.98(.86)$ & 0.635 \\
\hline & & we usually agree on meals and food choices. & $2.03(.87)$ & 0.574 \\
\hline
\end{tabular}

and 5. Based on the fitness indices found, the FHC scale has a highly favorable validity, and is approved for use in Iranian society. The models with factor loadings and factor correlations are shown in Figs. 1 and 2.

\section{Discussion}

Family health is one of the most important issues in any society, and its study is of considerable importance.
However, despite its importance, family health research has not attracted much attention in Iran, which can be due to the lack of suitable and practicable scales to measure family health. The present study was conducted to translate and validate the Persian version of the Family health climate scale in Iranian society. When a scale is translated or is to be used in another culture or society, it must be validated $[23,24]$.

Table 4 Confirmatory Factor analysis Fit indices for the FHC-PA scale in Iranian families

\begin{tabular}{|c|c|c|c|c|c|c|c|}
\hline Index sample & $(\mathrm{X} 2 / \mathrm{df}), p$ & RMSEA $(90 \% \mathrm{Cl})$ & CFI & GFI & AGFI & NFI & SRMR \\
\hline FHC-PA scale (calibration sample $n=300$ ) & $(2.72), p<0.001$ & $0.074(0.06-0.08)$ & 0.96 & 0.91 & 0.88 & 0.94 & 0.057 \\
\hline FHC-PA scale (validation sample $n=320$ ) & $(2.63), p<0.001$ & $0.074(0.06-0.08)$ & 0.97 & 0.92 & 0.88 & 0.95 & 0.058 \\
\hline
\end{tabular}


Table 5 Confirmatory Factor analysis Fit indices for the FHC-NU scale in Iranian families

\begin{tabular}{|c|c|c|c|c|c|c|c|}
\hline Index sample & $(\mathrm{X} 2 / \mathrm{df}), p$ & RMSEA $(90 \% \mathrm{Cl})$ & CFI & GFI & AGFI & $\mathrm{NFI}$ & SRMR \\
\hline FHC-NU scale (calibration sample $n=300$ ) & $(2.10), p<0.001$ & $0.059(0.05-0.07)$ & 0.98 & 0.92 & 0.89 & 0.96 & 0.050 \\
\hline FHC-NU scale (validation sample $n=320$ ) & $(1.85), p<0.001$ & $0.050(0.04-0.06)$ & 0.98 & 0.92 & 0.91 & 0.97 & 0.042 \\
\hline
\end{tabular}

The present study results showed that the Persian version of FHC scale (FHC-PA and FHC-NU) and its dimensions have favorable content validity, construct validity and reliability for use in Iranian society, and like the original scale, is approved [16].

For content validity of the scale, CVI was found 0.807 for FHC-PA and 0.893 for FHC-NU, which exceed 0.79 and indicate favorable CVI values [19]. The Farsi version of FHC scale also had favorable Cronbach's alpha coefficients (0.86 and 0.90 respectively), which exceeded the 0.7 limit and coefficients higher than 0.8 suggest that the scale has a high internal consistency [19].

Regarding construct validity, the exploratory factor analysis results showed that the translated scale totally matches the original scale in terms of number of dimensions and items within each, and elimination or replacement of the items was not necessary. This shows that the original scale was properly developed and can be used in Iranian society.

The CFA results showed that the original FHC model is also totally appropriate for use in Iranian families, and fitness indices obtained indicated total fitness of this scale and its dimensions. When conducting CFA, Lisrel usually provides recommendations for modification and improvement of the model that can be useful. However, given the model fit in the present study, change or replacement of items was not necessary.

The fact that a scale is translated and validated in another society has a favorable fit and has no need for

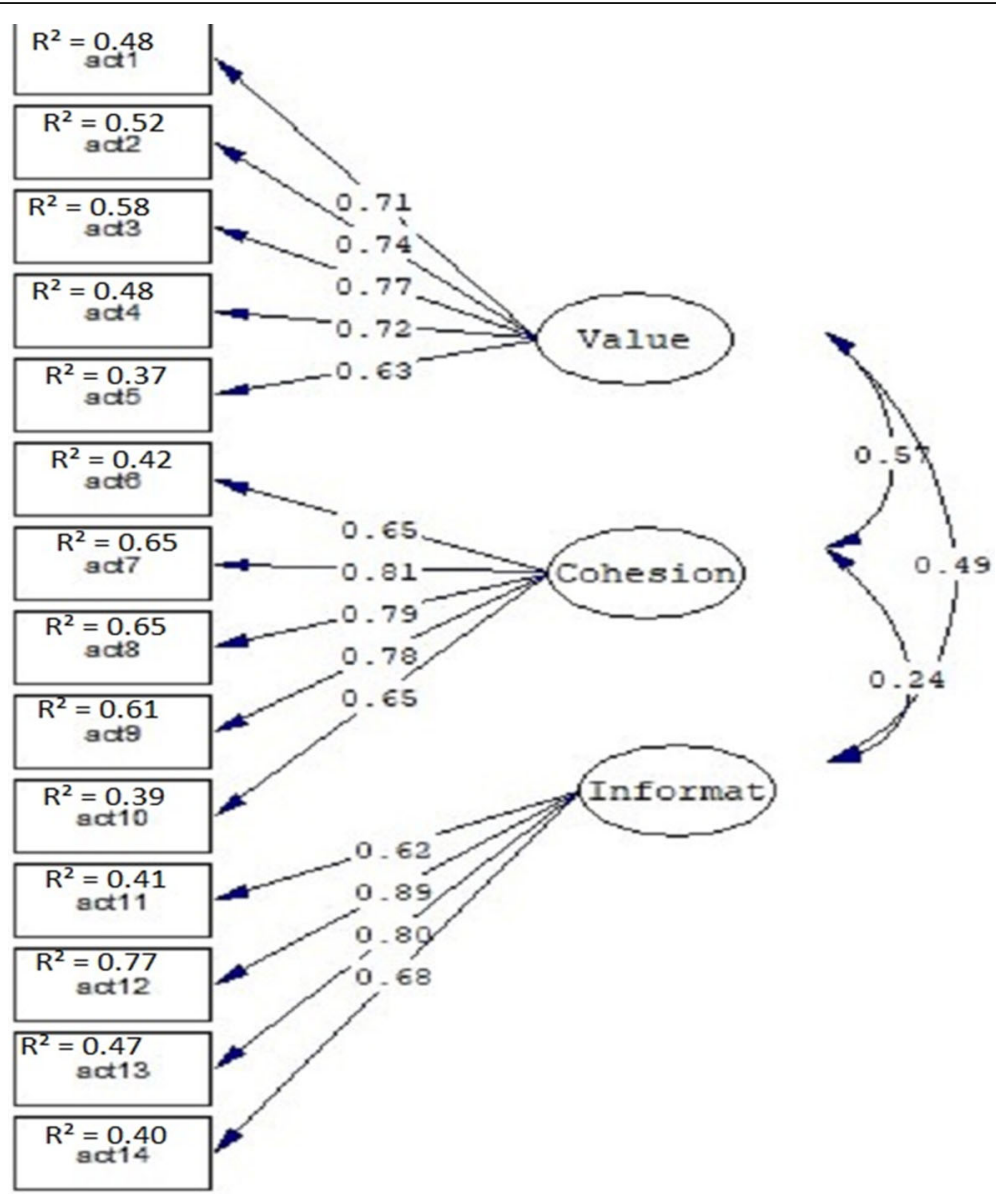

Fig. 1 FHC-PA - standardized factor loadings and interfactor correlations 


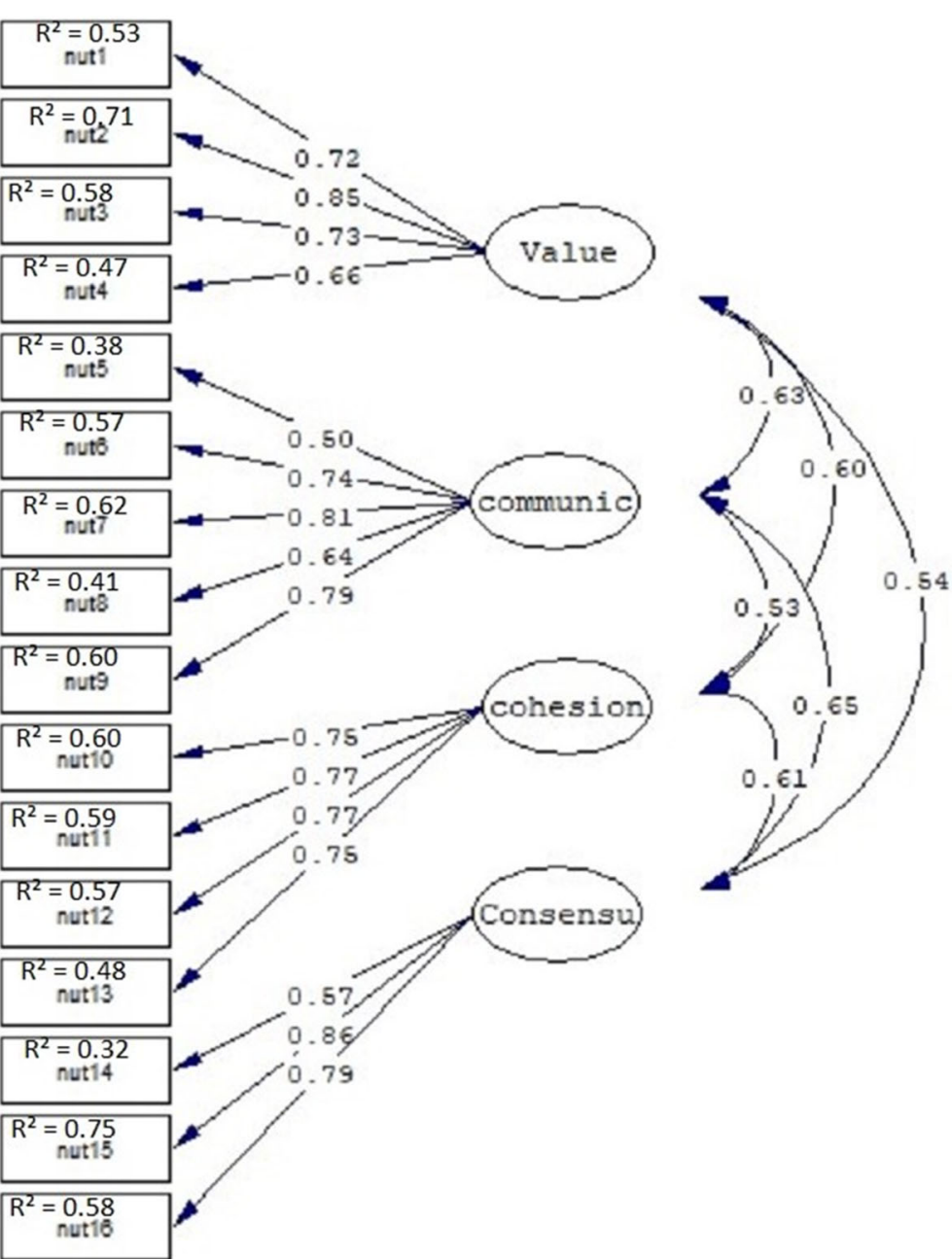

Fig. 2 FHC-NU - standardized factor loadings and interfactor correlations

change has also been found in other studies [23, 25], which agrees with the present study results. The concepts of nutrition and physical activity that are assessed by the FHC scale appear not to be widely different and can be used in different societies.

While the versions of the FHC-Scale seem to be consistent across languages and culture, other scales have not translated as easily. For example, in a study by Sajjadi et al. (2014) on translation and validation of the Uncertainty of Illness Scale in patients with cancer, some items have to be eliminated for use in Iranian society [26]. In a study conducted by Klemenc-Ketis et al. (2018) to validate a translated scale into Slovenian language, the initial model did not have a goodness of fit, but fitness indices became favorable with different dimensions in the translated version from the original scale [27]. These variable findings suggest how different a translated scale is from the original depends on several factors such as the concept studied, methodology and accuracy of developing the original tool, use of language, cultural differences, and other factors.

\section{Limitations}

One of the study limitations was sampling in one province only, which may affect generalizability of the results to the whole country. Another limitation was the selfreporting questionnaire, where some participants may not have accurately answered the questions.

\section{Conclusion}

The present study results showed that the FHC scale (including FHC-PA and FHC-NU scales) has favorable validity and reliability for use in Iranian society, and since it has relatively few items, it is easy for participants to complete and can be used to assess the health status of Iranian families. 


\section{Supplementary Information}

The online version contains supplementary material available at https://doi. org/10.1186/s12889-020-09931-8.

Additional file 1. Inter-items correlation matrix. This file included two tables that shows inter-items correlation matrix for both FHC-PA and FHC$\mathrm{NU}$ scales.

\section{Abbreviations}

FHC: Family health climate; FHC-PA: Family health climate - Physical activity; FHC-NU: Family health climate- Nutrition; SRMR: Standardized root-meansquare residual; NFI: Normed Fit Index; CFI: Comparative fit index; AGFI: Adjusted goodness of fit index; GFl: Goodness of fit index; RMSEA: Root-mean-square error of approximation; CVl: Content validity index; ICC: Interclass Correlation Coefficient

\section{Acknowledgements}

Researchers feel obliged to thank community health centers in Mashhad and Gonabad cities, and the Social Development and Health Promotion Research Center affiliated with Gonabad University of Medical sciences for funding this project (code:615). They also wish to thank all participants for their cooperation in this study.

\section{Authors' contributions}

Kh A: Collecting the participants' data and entering data to the SPSS software. JB: She was major contributor in revising and editing the manuscript. SM: major contributor in designing of the study, analysis and interpretation of the data, and was major contributor in drafting and writing the manuscript. MM: Was a major contributor in the manuscript writing. SL: she was also a major contributor in data collection (in Mashhad) and had a role in designing the study. It should be noted that all authors have read and approved the manuscript

\section{Funding}

This study was supported in by a Grant-in-Aid from the Social Development \& Health Promotion Research Center affiliated with Gonabad University of Medical Sciences (code: 615). The funder had no role in the design of the study and collection, management, analysis, and interpretation of the data and in writing the manuscript. The authors and their contributions to the manuscript are independent of the funder.

\section{Availability of data and materials}

The datasets used and/or analyzed during the current study are available from the corresponding author on reasonable request.

\section{Ethics approval and consent to participate}

The present study was approved by the Gonabad University of medical science ResearchEthics Committee (code: IR.GMU.REC.1395.102). Informed written consent was obtained from all participants above the age of 16 . Parental written consent was obtained on behalf of all participants below the age of 16 .

\section{Consent for publication}

Not applicable.

\section{Competing interests}

Not applicable.

\footnotetext{
Author details

${ }^{1}$ Social Development and Health Promotion Research Center, Gonabad University of Medical Sciences, Gonabad, Iran. ${ }^{2}$ Montana State University, College of Nursing, Bozeman, MT, USA. ${ }^{3}$ Department of Medical-Surgical Nursing, Faculty of Nursing, Social Development \& Health Promotion Research Center, Gonabad University of Medical Sciences, Gonabad, Iran. ${ }^{4}$ Department of Health Education and Health Promotion, School of Health, Social Development and Health Promotion Research Center, Gonabad University of Medical Sciences, Gonabad, Iran. ${ }^{5}$ Department of Gerontology,School of Nursing, Social Development and Health Promotion Research Center, Gonabad University of Medical Sciences, Gonabad, Iran.
}

Received: 28 September 2020 Accepted: 18 November 2020 Published online: 03 December 2020

\section{References}

1. Carr A. Family therapy: concepts, process and practice. Hoboken: Wiley; 2012.

2. Mazaheri A, Sadeghi MS, Heydari M. A comparison of family structure perception and ideal between parents and their young children. J Fam Res. 2008;4(4):329-51.

3. Christensen P. The health-promoting family: a conceptual framework for future research. Soc Sci Med. 2004;59(2):377-87.

4. Sadeghi M, Fatehizadeh M, Ahmadi A, Bahrami F, Etemadi O. Developing a model of healthy family based on an explorative mixed method research. J Fam Psychol. 2014;1(1):29-40.

5. Walsh AD, Hesketh KD, Hnatiuk JA, Campbell KJ. Paternal self-efficacy for promoting children's obesity protective diets and associations with children's dietary intakes. Int J Behav Nutr Phys Act. 2019;16(1):53.

6. Grochowski J. Families and health (2nd ed.). Los Angeles: SAGE Publications; 2014.

7. Kitzman-Ulrich H, Wilson DK, George SMS, Lawman H, Segal M, Fairchild A. The integration of a family systems approach for understanding youth obesity, physical activity, and dietary programs. Clin Child Fam Psychol Rev. 2010;13(3):231-53.

8. Walsh F. Family resilience: a framework for clinical practice. Fam Process. 2003:42(1):1-18.

9. Cox MJ, Paley B. Understanding families as systems. Curr Dir Psychol Sci. 2003;12(5):193-6.

10. Silva MC, Peduzzi M, Sangaleti CT, Silva D, Agreli HF, West MA, Anderson NR. Cross-cultural adaptation and validation of the teamwork climate scale. Rev Saude Publica. 2016;50:52.

11. Pirkis JE, Burgess PM, Kirk PK, Dodson S, Coombs TJ, Williamson MK. A review of the psychometric properties of the Health of the Nation Outcome Scales (HoNOS) family of measures. Health Qual Life Outcomes. 2005;3(1):76.

12. Walther J, Aldrian U, Stuger HP, Kiefer I, Ekmekcioglu C. Nutrition, lifestyle factors, and mental health in adolescents and young adults living in Austria. Int J Adolesc Med Health. 2014;26(3):377-86.

13. Niermann CY, Kremers SP, Renner B, Woll A. Family health climate and adolescents' physical activity and healthy eating: a cross-sectional study with mother-father-adolescent triads. PLoS One. 2015;10(11):e0143599.

14. Acevedo EO. The Oxford handbook of exercise psychology. New York: Oxford university press; 2012

15. Tamimi H, Noroozi A. Determinants of physical activity in high school girl students: study based on health promotion model (HPM). Journal of Health. 2016;6(5):527-37.

16. Niermann C, Krapf F, Renner B, Reiner M, Woll A. Family health climate scale (FHC-scale): development and validation. Int J Behav Nutr Phys Act. 2014; 11(1):30.

17. Wild D, Grove A, Martin M, Eremenco S, McElroy S, Verjee-Lorenz A, Erikson $P$. Principles of good practice for the translation and cultural adaptation process for patient-reported outcomes (PRO) measures: report of the ISPOR task force for translation and cultural adaptation. Value Health. 2005;8(2):94104.

18. Gheshlagh RG, Tabrizi KN, Dalvandi A, Ebadi A. Development and validation of resilience scale in patients with cardiovascular and respiratory diseases. IRCMJ. 2018;20(1):e14129.

19. Polit DF, Beck CT. Essentials of nursing research: appraising evidence for nursing practice. 9th ed. Philadelphia: Lippincott Williams \& Wilkins; 2017.

20. Arlot S, Celisse A. A survey of cross-validation procedures for model selection. Stat Surveys. 2010;4:40-79.

21. Brown TA. Confirmatory factor analysis for applied research. 2 nd ed. New York: Guilford publications; 2015.

22. Hooper D, Coughlan J, Mullen M. Structural equation modelling: guidelines for determining model fit. Electron J Bus Res Methods. 2008;6(1):53-60.

23. Moghadam LS, Foroughan M, Shahboulaghi FM, Ahmadi F, Sajjadi M, Farhadi A. Validity and reliability of the Persian version of the brief aging perceptions questionnaire in Iranian older adults. Clin Interv Aging. 2016;11:507.

24. Lanzarote-Fernandez MD, Lozano-Oyola JF, Gomez-de-Terreros-Guardiola M, Aviles-Carvajal I, Martinez-Cervantes RJ, Moreno JP. Spanish Version of the Family Health Behavior Scale: Adaptation and Validation. Int J Environ Res Public Health. 2019;16(5):810. 
25. Barati F, Sadeghmoghadam L, Sajjadi M, Nazari S, Bahri N. Validation of the Persian version of self-care tools for hypertension among older adults. Med Glas. 2019;16(2):338-43.

26. Sajjadi M, Rassouli M, Abbaszadeh A, Alavi Majd H, Zendehdel K

Psychometric properties of the Persian version of the Mishel's uncertainty in illness scale in patients with cancer. Eur J Oncol Nurs. 2014;18(1):52-7.

27. Klemenc-Ketis Z, Makivić I, Poplas-Susič A. Safety culture in the primary health care settings based on workers with a leadership role: the psychometric properties of the Slovenian-language version of the safety attitudes questionnaire-short form. BMC Health Serv Res. 2018;18(1):767.

\section{Publisher's Note}

Springer Nature remains neutral with regard to jurisdictional claims in published maps and institutional affiliations.

Ready to submit your research? Choose BMC and benefit from:

- fast, convenient online submission

- thorough peer review by experienced researchers in your field

- rapid publication on acceptance

- support for research data, including large and complex data types

- gold Open Access which fosters wider collaboration and increased citations

- maximum visibility for your research: over $100 \mathrm{M}$ website views per year

At BMC, research is always in progress.

Learn more biomedcentral.com/submissions 